\title{
Deguelin promotes apoptosis and inhibits angiogenesis of gastric cancer
}

\author{
HYUNSEUNG LEE* ${ }^{*}$ JU-HEE LEE* ${ }^{*}$ KYUNG HEE JUNG and SOON-SUN HONG \\ Department of Biomedical Sciences and Clinical Research Center, College of Medicine, Inha University, \\ 3-ga, Sinheung-dong, Jung-gu, Incheon 400-712, Republic of Korea
}

Received April 30, 2010; Accepted June 7, 2010

DOI: $10.3892 /$ or_00000942

\begin{abstract}
Gastric cancer is often diagnosed in locally advanced or metastatic stages, which preludes a poor prognosis. As only $10 \%$ of patients with advanced gastric cancer treated with chemotherapy survive 2 years, new approaches for preventing and controlling the disease are required. We therefore, assessed in gastric cancer cells the chemotherapeutic potential and mechanism of deguelin, a rotenoid of the flavonoid family isolated from several plant species. The effect of deguelin on the proliferation and apoptosis in the gastric cancer cells were assessed by MTT and flow cytometry. The growth of gastric cancer cells (SNU484, AGS and MKN-28) was inhibited by deguelin in a dose-dependent manner. $\mathrm{G}_{2} / \mathrm{M}$ phase arrest was induced by deguelin in gastric cancer cells. Deguelin $(1 \mu \mathrm{M})$ induced chromatin condensation and DNA fragmentation. Also the exposure to $1 \mu \mathrm{M}$ deguelin resulted in the increase in earlyapoptotic cells (Annexin V-positive/Propidium iodidenegative) after $24 \mathrm{~h}$, compared to the cells in the control medium (31 versus 12\%). Deguelin-induced apoptosis involved the caspase- 9 and caspase- 3 pathways in gastric cancer cells. Akt phosphorylation, hypoxia-inducible factor- $1 \alpha$ accumulation, and vascular endothelial growth factor expression in gastric cancer cells was inhibited by deguelin. Taken together, deguelin showed anticancer activity in gastric cancer cells, which is correlated with the inhibition of angiogenesis and induction of apoptosis. Deguelin may be a potential agent in inhibiting the progression of gastric cancer by virtue of its activity on these crucial cell characteristics.
\end{abstract}

Correspondence to: Dr Soon-Sun Hong, Department of Biomedical Sciences and Clinical Research Center, College of Medicine, Inha University, 3-ga, Sinheung-dong, Jung-gu, Incheon 400-712, Republic of Korea

E-mail: hongs@inha.ac.kr

${ }^{*}$ Contributed equally

Key words: deguelin, gastric cancer, angiogenesis, apoptosis

\section{Introduction}

Regardless of its decreasing global incidence and mortality, gastric cancer remains the second most common cause of cancer related death worldwide after lung cancer (1-3). It is the major cancer type in Asia, representing $20.8 \%$ of malignant neoplasms. Seventy-five percent of patients with gastric cancer are considered incurable at diagnosis because of disseminated disease. Even among patients with resectable tumors, recurrence rates are high, with $80-90 \%$ of patients ultimately presenting advanced cancer (4). Advanced gastric cancer patients have a poor prognosis with a median survival time, if untreated, of 3-5 months. Gastric cancer is often diagnosed in locally advanced or metastatic stages, creating a poor prognosis; only $10 \%$ of patients with advanced gastric cancer treated with chemotherapy survive 2 years (5). Systemic chemotherapy is widely accepted as palliative treatment, leading to objective responses, improvement of the quality of life, and prolonged survival. Based on response results of some combination chemotherapy regimens, advanced gastric cancer is believed to be a chemotherapy-sensitive disease.

Deguelin, a rotenoid isolated from several plant species including Mundulea sericea (Leguminosae), exhibits chemopreventive activities both in vitro and in vivo, and suppresses the formation of carcinogen-induced aberrant crypt foci in mouse colons and cigarette smoke-induced lung carcinogenesis (6). It also increases the sensitivity of leukemia cells to chemotherapeutic agents (7) and suppresses the growth of human colon cancer cells (8). Deguelin blocks the proliferation of premalignant and malignant human bronchial epithelial (HBE) cells by inducing apoptosis (9). It is active at nano-molar levels, with no apparent cytotoxicity to normal HBE cells. Furthermore, deguelin selectively blocks Akt activity in a phosphoinositide 3-kinase (PI3K)-dependent or -independent manner, thereby, diminishing the activity of a major anti-apoptotic pathway $(9,10)$. Additionally, deguelin strongly inhibits cyclooxygenase (COX)-2 expression in squamous HBE cells, without affecting COX-1 protein level (11).

While deguelin exhibits potential chemotherapeutic activities against several types of cancers, the effects of deguelin in gastric cancer remain unknown. In this study, therefore, we assessed deguelin as a chemotherapeutic agent against gastric cancer and investigated its mechanism. 


\section{Materials and methods}

Materials and reagents. FBS, RPMI-1640, Ham's F-12, penicillin-streptomycin and trypsin-EDTA were purchased from Hyclone Laboratories (Logan, UT, USA). Propidium iodide (PI), 3-(4,5-dimethylthiazol-2-yl)-2,5-diphenyltetrazolium bromide (MTT), and proteinase K were purchased from Sigma-Aldrich (St. Louis, MO, USA). RNase A was purchased from Qiagen (Valencia, USA). Deguelin was manufactured from the natural product rotenone (SigmaAldrich, Milwaukee, WI, USA) in a four-step reaction, dissolved in dimethyl sulfoxide (DMSO) at a stock concentration of $20 \mathrm{mM}$, and was stored at $-20^{\circ} \mathrm{C}$.

Cell culture. The human gastric cancer cell lines MKN-28, SNU-484 and AGS were purchased from the Korean Cell Line Bank (KCLB, Seoul, Korea). MKN-28 and SNU-484 cells were cultured in RPMI-1640 medium and AGS cells were cultured in Ham's F-12 medium, supplemented with $10 \%$ FBS and $1 \%$ penicillin/streptomycin. Cultures were maintained at $37^{\circ} \mathrm{C}$ in controlled humidified atmosphere composed of $95 \%$ air and $5 \% \mathrm{CO}_{2}$.

Cytotoxicity assay. Cell viability was performed by the MTT assay. Briefly, MKN-28, SNU-484 and AGS cells were plated at a density of $1-4 \times 10^{3}$ cells/well in 96-well plates for $24 \mathrm{~h}$. Then, the medium was removed, and the cells were treated with either DMSO as a control or various concentrations of deguelin. The final concentration of DMSO in the medium was $\leq 0.1 \%(\mathrm{v} / \mathrm{v})$. After the cells were incubated for $72 \mathrm{~h}, 20 \mu 1 \mathrm{MTT}$ solution $(5 \mathrm{mg} / \mathrm{ml})$ was added to each well for another $4 \mathrm{~h}$ at $37^{\circ} \mathrm{C}$. The formed formazan crystals were dissolved in DMSO (200 $\mu \mathrm{l} /$ well) by constant shaking for $5 \mathrm{~min}$. The plate was then read on a microplate reader at $540 \mathrm{~nm}$. Three replicate wells were used for each analysis. The median inhibitory concentration $\left(\mathrm{IC}_{50}\right.$, defined as the drug concentration at which cell growth was inhibited by $50 \%$ ) was assessed from the dose-response curves.

Cell cycle analysis. SNU-484 cells were plated in $100 \mathrm{~mm}-$ diameter culture dishes. The next day, cells were treated with various concentrations of deguelin or vehicle $(0.1 \%$ DMSO) for $24 \mathrm{~h}$. Floating and adherent cells were collected and fixed in cold $70 \%$ ethanol at $4^{\circ} \mathrm{C}$ overnight. After washing, the cells were subsequently stained with $20 \mu \mathrm{g} / \mathrm{ml} \mathrm{PI}$ and $100 \mu \mathrm{g} / \mathrm{ml}$ RNase A for $1 \mathrm{~h}$ in the dark and subjected to FACS analysis to determine the percentage of cells at specific phases of the cell cycle ( $\mathrm{subG}_{1}, \mathrm{G}_{0} / \mathrm{G}_{1}, \mathrm{~S}$, and $\mathrm{G}_{2} / \mathrm{M}$ ). Flow cytometric analysis was performed using a FACSCalibur flow cytometer (Becton-Dickinson, San Jose, CA, USA) equipped with a 488-nm argon laser. Events $(\sim 20,000)$ were evaluated for each sample and the cell cycle distribution was analyzed using Cell Quest software (Becton-Dickinson). The results are presented as the number of cells versus the amount of DNA as indicated by the intensity of the fluorescence signal. All the experiments were performed three times.

DAPI staining and TUNEL assay. To detect morphological evidence of apoptosis, cell nuclei were visualized following DNA staining with the fluorescent dye DAPI. SNU-484 cells were plated onto 18-mm cover glass in RPMI-1640 medium at $\sim 70 \%$ confluence for $24 \mathrm{~h}$. The cells were then treated with deguelin at $1 \mu \mathrm{M}$ for $24 \mathrm{~h}$. They were fixed with $1 \%$ paraformaldehyde, washed with PBS, and then stained with $2 \mu \mathrm{g} / \mathrm{ml}$ 4,6-diamidio-2-phenylindole (DAPI) for $20 \mathrm{~min}$ at $37{ }^{\circ} \mathrm{C}$. The stained cells were observed using fluorescence microscope (Carl Zeiss, Germany) with a peak excitation wavelength of $340 \mathrm{~nm}$. Terminal deoxynucleotidyl transferase-mediated nick end labeling (TUNEL) was performed following the manufacturer's protocol (TUNEL kit, Chemicon, USA).

Annexin $V$ assay. For flow cytometric analysis of apoptosis, SNU-484 cells were treated with deguelin for $24 \mathrm{~h}, 5 \times 10^{5}$ cells were removed from the culture, washed twice with cold PBS, and double stained with Annexin V-fluorescein isothiocyanate (FITC) and PI (BD Biosciences) in Annexinbinding buffer, followed by analysis on a FACSCalibur flow cytometer (Becton-Dickinson) equipped with a 488-nm argon laser. To avoid non-specific fluorescence from dead cells, live cells were gated using forward and side scatter.

Western blot analysis. Cells were washed three times with ice-cold phosphate-buffered saline (PBS) before lysis. Cells were lysed with buffer containing 1\% Triton X-100, 1\% Nonidet P-40, and the following protease and phosphatase inhibitors: aprotinin $(10(\mathrm{~g} / \mathrm{ml})$, leupeptin $(10 \mu \mathrm{g} / \mathrm{ml})(\mathrm{ICN}$ Biomedicals, Asse-Relegem, Belgium), phenylmethylsulfonyl fluoride (1.72 mM), NaF (100 (M), $\mathrm{NaVO}_{3}$ (500 (M) and $\mathrm{Na}_{4} \mathrm{P}_{2} \mathrm{O}_{7}(500 \mu \mathrm{g} / \mathrm{ml})$ (Sigma-Aldrich). Equal amounts of protein were separated by $10 \%$ sodium dodecyl sulfate-polyacrylamide gel electrophoresis, transferred onto nitrocellulose membranes and the protein transfer was checked by Ponceau $\mathrm{S}$ solution staining (Sigma-Aldrich). Immunostaining of the blots was performed using the primary antibodies, followed by the secondary antibody conjugated to horseradish peroxidase and detection by enhanced chemiluminescence reagent (Amersham Biosciences, Piscataway, NJ, USA). Restore Western blot striping buffer (Pierce, Rockford, IL, USA) was used to strip an immunostained blot before restaining for a second protein. Primary antibodies were the mouse monoclonal antibodies for anti-caspase-9 (Santa Cruz Biotechnology, Santa Cruz, CA, USA), anti-HIF-1 $\alpha$ (BD Biosciences), and anti-PARP-1 and anti-cleaved caspase-3 (Cell Signaling Technologies, Danvers, MA, USA). The secondary antibodies were purchased from Amersham Biosciences.

$R T$-PCR. SNU-484 cells were seeded in $100 \mathrm{~mm}$-diameter culture dishes and continually incubated for $24 \mathrm{~h}$. Then, cells were treated with various concentrations of deguelin and $100 \mu \mathrm{M} \mathrm{CoCl}_{2}$ for hypoxic conditions in a complete medium for $24 \mathrm{~h}$. Total RNA from the cells was isolated using TRIzol reagent (Invitrogen) according to the manufacturer's instructions. Single-strand cDNA was synthesized from $1 \mu \mathrm{g}$ total RNA using a reverse transcription system (Promega, Madison, WI, USA) according to the manufacturer's instructions in a total volume of $20 \mu \mathrm{l}$. Equal amounts of cDNA were subsequently amplified by PCR in a $25 \mu \mathrm{l}$ reaction volume containing $1 \mathrm{X}$ PCR reaction buffer, $200 \mu \mathrm{M}$ dNTPs, 0.5 pmol specific primer for each gene and 1 unit of Taq DNA polymerase (Takara Biotech, Shiga, Japan). The 
annealing temperature was $60^{\circ} \mathrm{C}$ for VEGF, $55^{\circ} \mathrm{C}$ for $\mathrm{HIF}-1 \alpha$ and $55^{\circ} \mathrm{C}$ for glyceraldehyde-3-phosphate dehydrogenase (GAPDH). GAPDH was used as an internal control of cDNA amplification. Amplification products were separated on $1.5 \%$ agarose gels and visualized by ethidium bromide staining under ultraviolet transillumination. The primer sequences were as follows: (sense) 5'-AGCTACTGCCATCC AATCGC-3' and (antisense) 5'-GGGCGAATCCAATTC CAAGAG-3' for VEGF; (sense) 5'-CAGAAGATACAAGT AGC CTC-3' and (antisense) 5'-CTGCTGGAATACTGTAA CTG-3' for HIF-1 $\alpha$; (sense) 5'-ACCACAGTCCATGCCAT CAC-3' and (antisense) 5'-TCCACCACCCTGTTGCT GTA-3' for GAPDH.

Statistical analysis. The Student's t-test was used for analyzing statistical significance between the two groups. The P-value was considered significant at $<0.05$.

\section{Results}

Deguelin inhibits the proliferation of gastric cancer cells. We first assessed the effect of deguelin on cell proliferation by treating AGS, SNU-484 and MKN-28 gastric cancer cells with a range of various deguelin concentrations. All the concentrations of deguelin tested inhibited cell growth, with statistically significant differences after 72-h exposure. Cell growth was inhibited in a dose-dependent manner (Fig. 1). The $\mathrm{IC}_{50}$ of deguelin was $0.45,1.38$ and $0.06 \mu \mathrm{M}$ in SNU484, AGS, and MKN-28 cells, respectively.

Deguelin induces $G_{2} / M$ phase arrest and apoptosis in gastric cancer cells. Deguelin inhibits the growth of cells by inducing cell cycle arrest in the $\mathrm{G}_{2} / \mathrm{M}$ phase in lung and leukaemia cells $(10,12)$. To investigate whether the anti-proliferative effects of deguelin were accompanied by cell cycle arrest in gastric cancer cells, the relative DNA content of SNU-484 cells was measured using flow cytometry. Deguelin treatment resulted in an evident increase in $\mathrm{G}_{2} / \mathrm{M}$ phase population together with a concomitant decrease in $\mathrm{G}_{0} / \mathrm{G}_{1}$. As shown in Fig. 2A, there was little change in the cell cycle until the deguelin concentration was $2.5 \mu \mathrm{M}$. SNU-484 cells treated with 5 and $10 \mu \mathrm{M}$ deguelin for $24 \mathrm{~h}$ had 38.6 and $55 \%$ cells in $\mathrm{G}_{2} / \mathrm{M}$ phase, respectively, as compared with only $23.8 \%$ in the control. Conversely, $\mathrm{G}_{0} / \mathrm{G}_{1}$ phase population was decreased to $31.4 \%$ and $11 \%$ in 5 and $10 \mu \mathrm{M}$ deguelin, respectively, as compared with $49.9 \%$ in the control. The percentage of $\mathrm{SubG}_{1}$ phase population increased in a dosedependent manner, confirming its apoptotic effect on SNU484 cells.

Nuclei condensation and TUNEL reaction were studied to investigate whether cell death was a result of apoptosis in SNU-484 cells. To characterize the cell death induced by deguelin, we examined nuclear morphology of dying cells with a fluorescent DNA-binding agent, DAPI. SUN-484 cells treated with deguelin displayed typical morphological features of apoptotic cells, with condensed and fragmented nuclei, while homogeneous nuclear chromatin was evident in control cells. The induction of apoptosis by deguelin was confirmed by TUNEL assay. TUNEL assay based on labelling of DNA strand breaks generated during apoptosis revealed that deguelin induced apoptosis in SNU-484 cells (Fig. 2B).
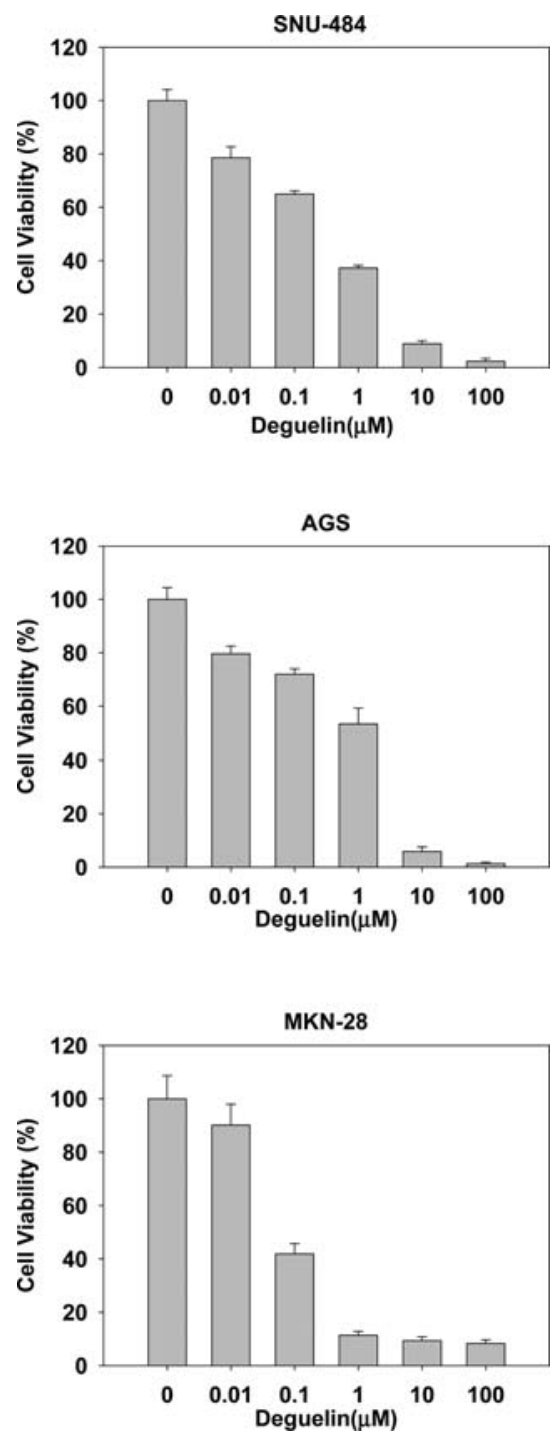

Figure 1. Effects of deguelin on proliferation of gastric cancer cells. SNU-484, AGS and MKN-28 cells were seeded in 96-well culture plates (1-4x10 cells/well). After incubation for $24 \mathrm{~h}$, the cells were treated with various concentrations of deguelin or $0.1 \%$ DMSO as a control. After incubation for $72 \mathrm{~h}$, they were subjected to MTT assay. Results are expressed as a percentage for proliferation of DMSO-treated cells (control). Each value is the mean $( \pm \mathrm{SD})$ from triplicate wells.

Deguelin promotes early-apoptosis of gastric cancer cells. Cells treated with $1 \mu \mathrm{M}$ deguelin for $24 \mathrm{~h}$ showed apoptosisrelated changes (chromatin condensation, TUNEL-positive cells), prompting the examination of whether deguelin could induce apoptosis in gastric cancer cells. SNU-484 cells were incubated with $0.1-10 \mu \mathrm{M}$ deguelin for $24 \mathrm{~h}$ to evaluate the dose-dependency of the pro-apoptotic effect of deguelin (Fig. 3A). Induction of apoptosis was observed by the treatment of $0.1 \mu \mathrm{M}$ deguelin. Exposure to $1-\mu \mathrm{M}$ deguelin resulted in a $19 \%$ increase in early-apoptotic cells (Annexin V-positive/Pro-pidium iodide-negative) after $24 \mathrm{~h}$, compared to the cells in the control medium (31 versus $12 \%$ ). Deguelin seemed to increase apoptosis and not necrosis as evidenced by the increased population of early-apoptotic cells (Fig. 3B). Additional evidence for an increase in apoptosis was an increase in total percentage of Annexin Vpositive cells, which included late apoptotic cells. 

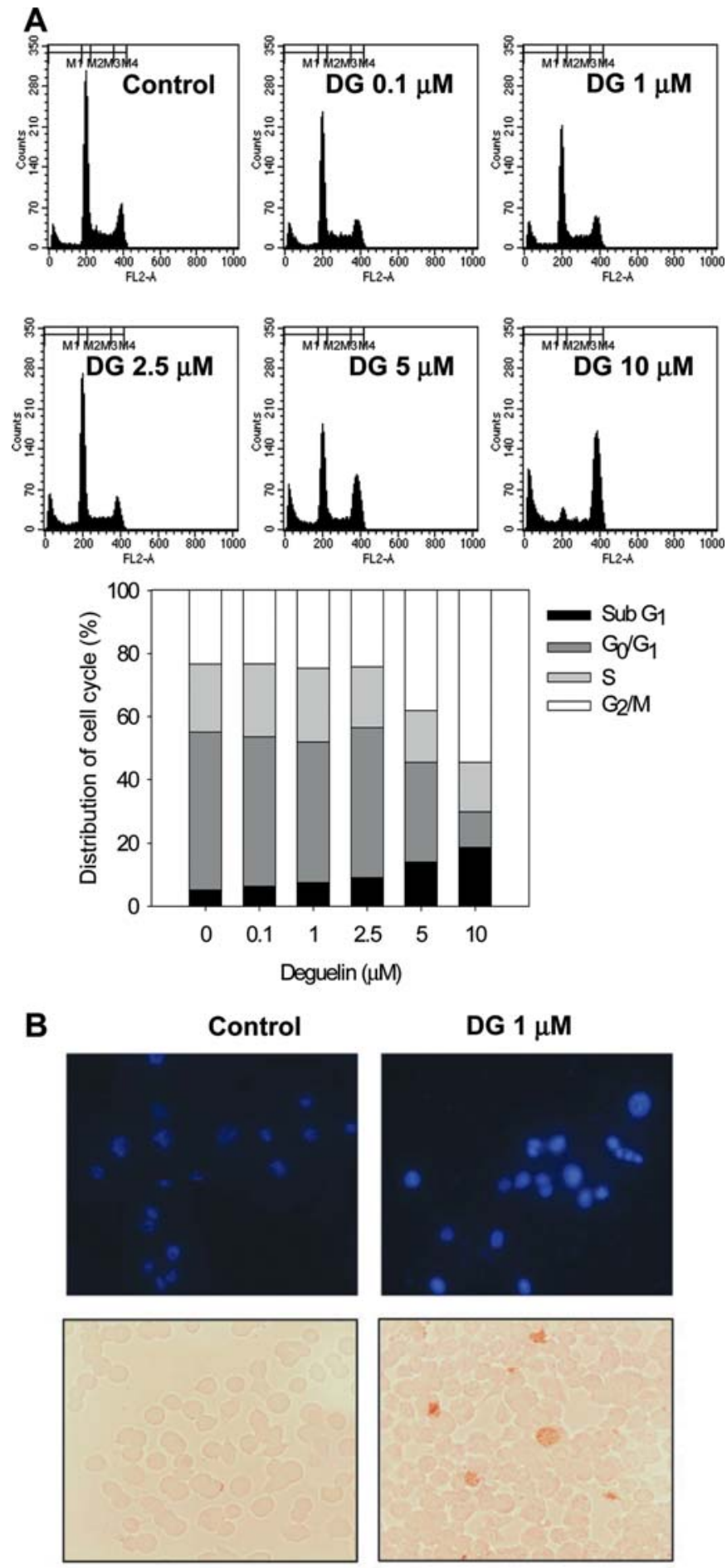

Figure 2. Deguelin induces $\mathrm{G}_{2} / \mathrm{M}$ phase arrest and apoptosis in gastric cancer cells. SNU-484 cells were incubated with the various concentration of deguelin for $24 \mathrm{~h}$ and analyzed by flow cytometry for DNA content. The percentages of cells in specific phases of cell cycle by means of PI staining were determined. Each value is the mean $( \pm \mathrm{SD})$ from triplicate samples (A). DAPI Staining (top of B); condensed nuclei were revealed by DAPI staining. TUNEL assay (bottom of B); condensed and marginated chromatin was shown to be stained dark brown.

To determine if the pro-apoptotic effect of deguelin was accompanied by activation of caspase, processing of caspase- 9 and caspase- 3 was examined by Western blot analysis. Treatment of SNU-484 cells with deguelin for $24 \mathrm{~h}$ increased caspase- 3 and caspase- 9 cleavage. To confirm the activation of caspase-3, we examined cleavage of the DNA repair enzyme poly(ADP-ribose) polymerase (PARP), one of the major substrates of activated caspase- 3 , which is cleaved into an N-terminal DNA-binding domain and C-terminal catalytic domain. Deguelin-induced cleavage of PARP was also observed in a dose-dependent manner (Fig. 3C).

Effect of deguelin on hypoxia-inducible factor-1 a (HIF-1a) accumulation and vascular endothelial growth factor (VEGF) expression in gastric cancer cells. Since deguelin is a natural chemotherapeutic agent (14-17), we investigated whether 
A

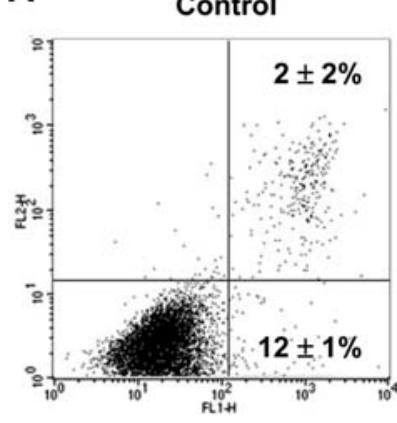

DG $1 \mu \mathrm{M}$

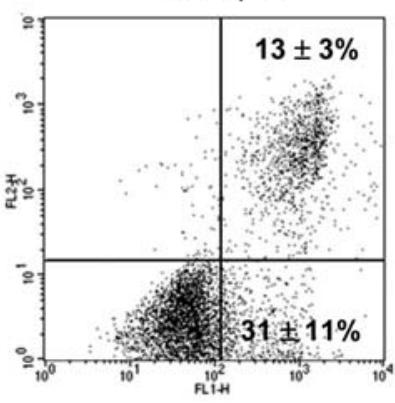

DG $0.1 \mu \mathrm{M}$

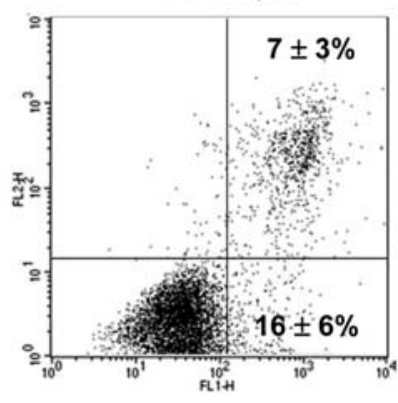

DG $10 \mu \mathrm{M}$

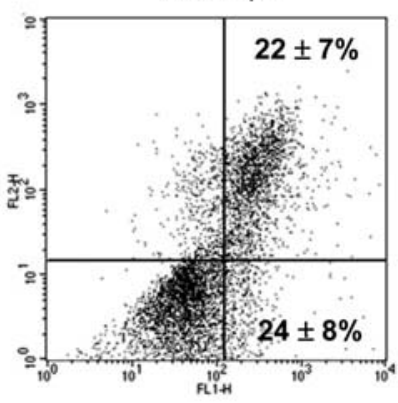

B

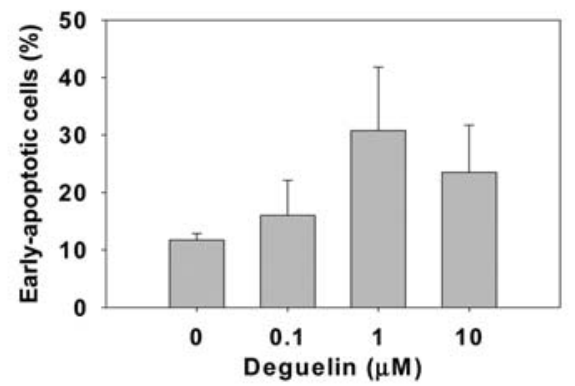

C $\begin{array}{lllll}\text { Deguelin }(\mu \mathrm{M}) \quad-\quad & 0.1 & 1 & 10\end{array}$

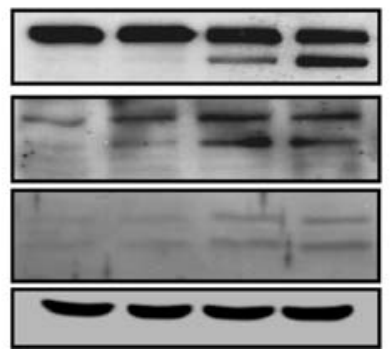

PARP

Cleaved

Caspase 9

Cleaved

Caspase 3

$\alpha$-tubulin

Figure 3. Deguelin promotes early-apoptosis of gastric cancer cells. SNU-484 cells were treated with various concentrations of deguelin for $24 \mathrm{~h}$. Apoptosis was determined by flow cytometric analysis using Annexin V-FITC and PI staining. (A) The percentage of early-apoptotic cells was measured by the percentage of Annexin V-positive/PI-negative cells after incubation with various concentration of deguelin for $24 \mathrm{~h}$. (B) Representative flow cytometric analysis of apoptosis in SNU-484 cells. Numbers in the quadrants indicate the percentage of cells labelled with Annexin V-FITC (bottom right) or Annexin V-FTIC and PI (top right). Each value is the mean ( \pm SD) from triplicate samples. (C) The expression of PARP, caspase- 9 and caspase-3 cleavage fragments were evaluated in SNU-484 cells after $24 \mathrm{~h}$ of deguelin treatment.

deguelin exerted an anti-angiogenic effect in gastric cancer cells. HIF-1 transcription activity and the expression of angiogenic factors are subjected to regulation by the PI3K/ AKT pathway. Deguelin was recently recognized as a PI3K pathway inhibitor $(9,10,12-14)$. Therefore, we investigated the effects of deguelin on the phosphorylation of Akt, a downstream target of PI3K in gastric cancer cells. SNU-484 cells were treated with $0.1-10 \mu \mathrm{M}$ deguelin for $16 \mathrm{~h}$ and then stimulated by $5 \%$ fetal bovine serum (FBS) for $30 \mathrm{~min}$.
Treatment with deguelin decreased phosphorylation of $\mathrm{Akt}^{\mathrm{ser} 473}$ in a dose-dependent manner (Fig. 4A). However, total Akt expression was unchanged by deguelin.

Deguelin has been reported to be an anti-angiogenic drug that targets HIF-1 $\alpha$ in lung cancer (31-35). To determine the effect of deguelin on expression of angiogenic factors in gastric cancer cells, VEGF and HIF-1 $\alpha$ expression were investigated by RT-PCR. After treatment of deguelin for $2 \mathrm{~h}$, SNU-484 cells were treated with the hypoxia mimicking 
A

$5 \%$ FBS

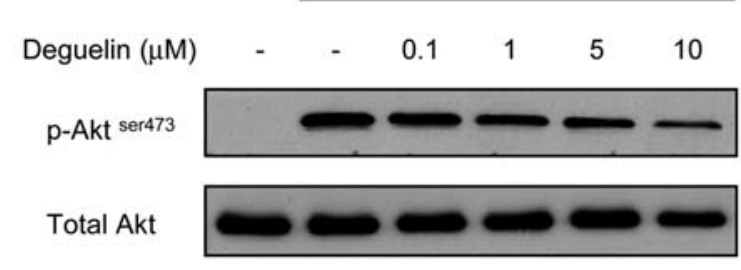

B

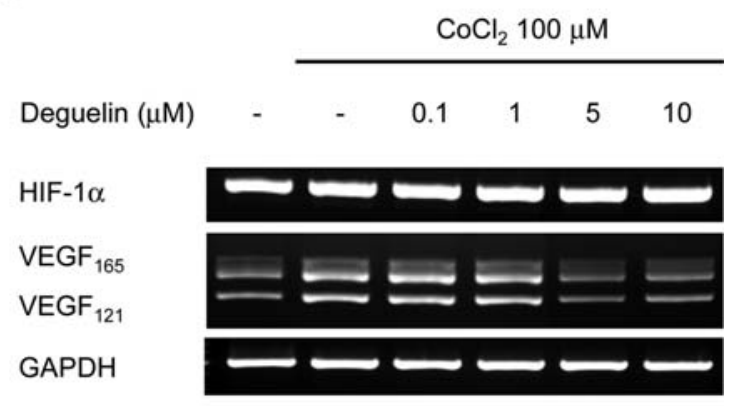

C

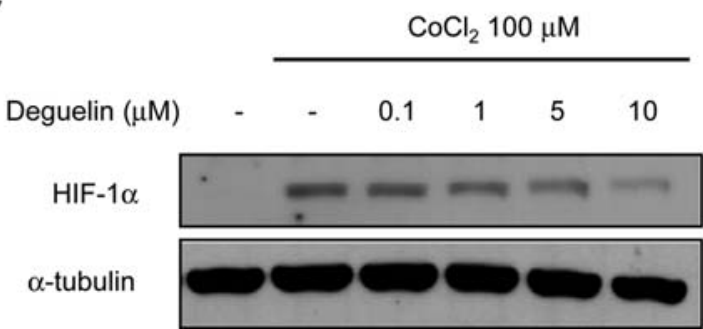

Figure 4. Effect of deguelin on PI3K/Akt pathway and the angiogenic factor (A) SNU-484 cells were treated with various concentration of deguelin for $24 \mathrm{~h}$ and stimulated by treatment with $5 \%$ FBS for $30 \mathrm{~min}$. Deguelin treatment inhibited Akt phosphorylation in SNU-484 cells. (B) Treatment of SNU-484 cells with various concentration $(0.01-1 \mu \mathrm{M})$ deguelin for $24 \mathrm{~h}$ under $\mathrm{CoCl}_{2}$-induced hypoxic conditions reduced the expression of VEGF in a dose-dependent manner. (C) SNU-484 cells were treated with various concentrations of deguelin under hypoxic conditions by the treatment of $100 \mu \mathrm{M} \mathrm{CoCl}_{2}$ to for $24 \mathrm{~h}$. Deguelin abolished the stabilization of HIF-1 $\alpha$. One representative experiment from three independent experiments was shown.

agent $\mathrm{CoCl}_{2}$ for $24 \mathrm{~h}$. Deguelin treatment reduced mRNA expression of VEGF in a dose-dependent manner, whereas the expression of HIF- $1 \alpha$ remained unchanged (Fig. 4B).

We examined whether deguelin might play a role in stabilization of HIF-1 $\alpha$. After treatment of deguelin for $2 \mathrm{~h}$, SNU484 cells were treated with $\mathrm{CoCl}_{2}$ for $24 \mathrm{~h}$. As a result, deguelin abolished $\mathrm{CoCl}_{2}$-induced HIF- $1 \alpha$ accumulation (Fig. 4C).

\section{Discussion}

Gastric cancers remain one of the major causes of cancer deaths around the world $(1,2)$. Among the chemotherapeutic drugs for gastric cancer, 5-fluorouracil remains the primary agent in clinical use and, to date, many new drugs have been in clinical trials. Recently, the PI3K/Akt pathway has been implicated in the development of multiple human cancers. The PI3K pathway plays a critical role in cell progression by promoting cell proliferation and inhibiting apoptosis. Akt, an important and probably essential downstream component of PI3K-mediated oncogenic signalling, provides a critical cell survival signal for tumor progression by phosphorylating a number of proteins involved in cell cycle regulation and proapoptotic factors $(13,19)$. Overexpression and/or activation of Akt have also been detected in gastric cancer (20). In addition, phosphatase and tensin homolog (PTEN), a tumor suppressor gene product, negatively regulates Akt. A PTEN gene mutation has been identified in gastric cancer, which may lead to Akt activation $(21,22)$. Activation of Akt has been suggested to be associated with chemoresistance of human tumors including gastric cancer $(23,24)$.

The ability of deguelin to inhibit PI3K/Akt-mediated signalling pathways contributes to an anti-proliferative effect. Deguelin is a novel PI3K inhibitor and potential chemopreventive agent in breast, skin, colon, and lung cancers $(12,17)$, and effectively prevents tobacco carcinogen-induced lung carcinogenesis by blocking PI3K/Akt activation $(6,14)$. $\mathrm{We}$, therefore, investigated whether deguelin, as a cancer chemotherapeutic agent or inhibitor of carcinogenesis, could inhibit proliferation of gastric cancer cells and PI3K/Akt activation. Proliferation of MKN-28, AGS, and SNU-484 cells were inhibited in a dose-dependent manner by deguelin treatment, and Akt phosphorylation were attenuated in SNU484 cells.

In a previous study, premalignant and malignant human HBE cells treated with deguelin were observed to accumulate in the $\mathrm{G}_{2} / \mathrm{M}$ phase of the cell cycle (9). The researchers also observed that deguelin promoted cell cycle arrest in colon and lung cancer cells, which was followed by apoptosis induction. In colon cancer cells, deguelin arrested the cell cycle at the $\mathrm{G}_{0} / \mathrm{G}_{1}$ phase (8). In this study, we found that SNU484 cells treated with deguelin were arrested at the $G_{2} / M$ phase. This cell cycle arrest may have been due to the binding of deguelin to the heat shock protein 90 (Hsp90)-mediated regulation of the cell cycle and subsequent disruption of Hsp90 (25-27).

Previously, we reported that deguelin induces apoptosis in hepatocellular carcinoma cells (28). We further investigated whether deguelin could promote apoptosis of gastric cancer cells. In this study, we found clear evidence from flow cytometry and Western blot analysis that deguelin induces apoptosis in SNU-484 cells. We demonstrated the increase of early apoptosis in the presence of $1 \mu \mathrm{M}$ deguelin, indicating that deguelin may induce apoptosis in SNU-484 cells. We determined that this apoptosis was mediated by caspase- 3 and caspase-9 pathway. These data support the potent apoptotic effects of deguelin on gastric cancer.

Angiogenesis is essential for tumor growth and metastasis. Tumor neovascularization depends on the production of specific angiogenic factors, either by host or tumor cells, which shifts the angiogenic balance toward a pro-angiogenic phenotype. Much attention has been focused on the VEGF family as the major factor that contributes to angiogenesis and metastasis in numerous tumor types, and VEGF overexpression has been associated with tumor progression and poor clinical outcome $(29,30)$. Hypoxia, a characteristic of solid tumors, is an important inducer of VEGF. The transcription factor hypoxia-inducible factor 1 (HIF-1), a heterodimer consisting of a HIF- $1 \alpha$ and a HIF- $1 \beta$ subunit, is an 
important upstream mediator of VEGF expression in cancer cells (18).

Drug development targeting HIF-1 $\alpha$ has evoked extensive interest in cancer therapy. HIF- $1 \alpha$ is a new target for the antiangiogenic therapy of gastric cancer. Deguelin has been reported to be an anti-angiogenic agent that targets HIF-1 $\alpha$ in lung cancer (31-35). Earlier studies showed that the PI3K/ Akt/mTOR pathway regulates HIF- $1 \alpha$ protein translation through mTOR $(36,37)$. Therefore, we investigated the antiangiogenic activities of deguelin in gastric cancer cells. We observed that deguelin inhibited angiogenesis via downregulation of the VEGF mRNA and destabilization of HIF-1 $\alpha$ protein in SNU-484 cells. This may have been due to a ubiquitin-mediated degradation of HIF- $1 \alpha$ by the binding of deguelin to Hsp90 and the disruption of Hsp90 function, as observed in previous studies $(27,32-34)$.

Taken together, our data indicate that deguelin has anticancer activity, which is correlated with the inhibition of angiogenesis and induction of apoptosis in gastric cancer. Deguelin may be a potential agent in inhibiting the progression of gastric cancer by virtue of its activity on these crucial cell characteristics.

\section{Acknowledgements}

This study was supported by Inha University Grant.

\section{References}

1. Crew KD and Neugut AI: Epidemiology of gastric cancer. World J Gastroenterol 12: 354-362, 2006.

2. Dicken BJ, Bigam DL, Cass C, Mackey JR, Joy AA and Hamilton SM: Gastric adenocarcinoma: review and considerations for future directions. Ann Surg 241: 27-39, 2005.

3. Parkin DM, Bray F, Ferlay J and Pisani P: Global cancer statistics, 2002. CA Cancer J Clin 55: 74-108, 2005.

4. Clarke JS, Cruze K, El Farra S and Longmire WP Jr: The natural history and results of surgical therapy for carcinoma of the stomach. An analysis of 250 cases. Am J Surg 102: 143-152, 1961

5. Janunger KG, Hafstrom L, Nygren $P$ and Glimelius B: A systematic overview of chemotherapy effects in gastric cancer. Acta Oncol 40: 309-326, 2001.

6. West KA, Linnoila IR, Belinsky SA, Harris CC and Dennis PA: Tobacco carcinogen-induced cellular transformation increases activation of the phosphatidylinositol 3'-kinase/Akt pathway in vitro and in vivo. Cancer Res 64: 446-451, 2004.

7. Geeraerts B, Vanhoecke B, Vanden Berghe W, Philippe J, Offner F and Deforce D: Deguelin inhibits expression of IkappaBalpha protein and induces apoptosis of B-CLL cells in vitro. Leukemia 21: 1610-1618, 2007.

8. Murillo G, Salti GI, Kosmeder JW II, Pezzuto JM and Mehta RG: Deguelin inhibits the growth of colon cancer cells through the induction of apoptosis and cell cycle arrest. Eur J Cancer 38: 2446-2454, 2002.

9. Chun KH, Kosmeder JW III, Sun S, et al: Effects of deguelin on the phosphatidylinositol 3-kinase/Akt pathway and apoptosis in premalignant human bronchial epithelial cells. J Natl Cancer Inst 95: 291-302, 2003.

10. Bortul R, Tazzari PL, Billi AM, et al: Deguelin, A PI3K/AKT inhibitor, enhances chemosensitivity of leukaemia cells with an active PI3K/AKT pathway. Br J Haematol 129: 677-686, 2005.

11. Lee HY, Suh YA, Kosmeder JW, Pezzuto JM, Hong WK and Kurie JM: Deguelin-induced inhibition of cyclooxygenase-2 expression in human bronchial epithelial cells. Clin Cancer Res 10: 1074-1079, 2004.

12. Lee HY: Molecular mechanisms of deguelin-induced apoptosis in transformed human bronchial epithelial cells. Biochem Pharmacol 68: 1119-1124, 2004.

13. Hennessy BT, Smith DL, Ram PT, Lu Y and Mills GB: Exploiting the PI3K/AKT pathway for cancer drug discovery. Nat Rev Drug Discov 4: 988-1004, 2005.
14. Lee HY, Oh SH, Woo JK, et al: Chemopreventive effects of deguelin, a novel Akt inhibitor, on tobacco-induced lung tumorigenesis. J Natl Cancer Inst 97: 1695-1699, 2005.

15. Gerhauser C, Lee SK, Kosmeder JW, et al: Regulation of ornithine decarboxylase induction by deguelin, a natural product cancer chemopreventive agent. Cancer Res 57: 3429-3435, 1997.

16. Hail N Jr and Lotan R: Apoptosis induction by the natural product cancer chemopreventive agent deguelin is mediated through the inhibition of mitochondrial bioenergetics. Apoptosis 9: 437-447, 2004

17. Udeani GO, Gerhauser C, Thomas CF, et al: Cancer chemopreventive activity mediated by deguelin, a naturally occurring rotenoid. Cancer Res 57: 3424-3428, 1997.

18. Semenza GL: Targeting HIF-1 for cancer therapy. Nat Rev Cancer 3: 721-732, 2003.

19. Shaw RJ and Cantley LC: Ras, PI(3)K and mTOR signalling controls tumour cell growth. Nature 441: 424-430, 2006.

20. Staal SP: Molecular cloning of the akt oncogene and its human homologues AKT1 and AKT2: amplification of AKT1 in a primary human gastric adenocarcinoma. Proc Natl Acad Sci USA 84: 5034-5037, 1987.

21. Samuels Y, Wang Z, Bardelli A, et al: High frequency of mutations of the PIK3CA gene in human cancers. Science 304: 554, 2004

22. Sato K, Tamura G, Tsuchiya T, et al: Analysis of genetic and epigenetic alterations of the PTEN gene in gastric cancer. Virchows Arch 440: 160-165, 2002.

23. Oki E, Baba H, Tokunaga E, et al: Akt phosphorylation associates with LOH of PTEN and leads to chemoresistance for gastric cancer. Int J Cancer 117: 376-380, 2005.

24. Yu HG, Ai YW, Yu LL, et al: Phosphoinositide 3-kinase/Akt pathway plays an important role in chemoresistance of gastric cancer cells against etoposide and doxorubicin induced cell death. Int J Cancer 122: 433-443, 2008.

25. Aligue R, Akhavan-Niak $\mathrm{H}$ and Russell P: A role for Hsp90 in cell cycle control: wee 1 tyrosine kinase activity requires interaction with Hsp90. EMBO J 13: 6099-6106, 1994.

26. Burrows F, Zhang H and Kamal A: Hsp90 activation and cell cycle regulation. Cell Cycle 3: 1530-1536, 2004.

27. Oh SH, Woo JK, Yazici YD, et al: Structural basis for depletion of heat shock protein 90 client proteins by deguelin. J Natl Cancer Inst 99: 949-961, 2007.

28. Lee JH, Lee DH, Lee HS, Choi JS, Kim KW and Hong SS: Deguelin inhibits human hepatocellular carcinoma by antiangiogenesis and apoptosis. Oncol Rep 20: 129-134, 2008.

29. Ferrara N: VEGF and the quest for tumour angiogenesis factors. Nat Rev Cancer 2: 795-803, 2002.

30. Hicklin DJ and Ellis LM: Role of the vascular endothelial growth factor pathway in tumor growth and angiogenesis. J Clin Oncol 23: 1011-1027, 2005.

31. Kim WY, Chang DJ, Hennessy B, et al: A novel derivative of the natural agent deguelin for cancer chemoprevention and therapy. Cancer Prev Res 1: 577-587, 2008.

32. Kim WY, Oh SH, Woo JK, Hong WK and Lee HY: Targeting heat shock protein 90 overrides the resistance of lung cancer cells by blocking radiation-induced stabilization of hypoxiainducible factor-1alpha. Cancer Res 69: 1624-1632, 2009.

33. Oh SH, Woo JK, Jin Q, et al: Identification of novel antiangiogenic anticancer activities of deguelin targeting hypoxiainducible factor-1 alpha. Int J Cancer 122: 5-14, 2008.

34. Woo JK, Choi DS, Tran HT, Gilbert BE, Hong WK and Lee HY: Liposomal encapsulation of deguelin: evidence for enhanced antitumor activity in tobacco carcinogen-induced and oncogenic K-ras-induced lung tumorigenesis. Cancer Prev Res 2: 361-369, 2009.

35. Zhang Q, Tang X, Zhang ZF, Velikina R, Shi S and Le AD: Nicotine induces hypoxia-inducible factor-1alpha expression in human lung cancer cells via nicotinic acetylcholine receptor-mediated signaling pathways. Clin Cancer Res 13: 4686-4694, 2007.

36. Bernardi R, Guernah I, Jin D, et al: PML inhibits HIF-1alpha translation and neoangiogenesis through repression of mTOR. Nature 442: 779-785, 2006.

37. Pore N, Jiang Z, Shu HK, Bernhard E, Kao GD and Maity A: Akt1 activation can augment hypoxia-inducible factor-1alpha expression by increasing protein translation through a mammalian target of rapamycin-independent pathway. Mol Cancer Res 4: 471-479, 2006. 